\title{
The influence of marital status on survival in patients with oral tongue squamous cell carcinoma
}

\author{
Wei Sun ${ }^{1, *}$, Zeting Qiu ${ }^{2, *}$, Wulin Tan ${ }^{2, *}$, Zhongqi Liu ${ }^{1}$, Zhongxing Wang ${ }^{2}$, Wenqi \\ Huang ${ }^{2, *}$ and Minghui $\mathrm{CaO}^{1, \#}$ \\ ${ }^{1}$ Department of Anesthesiology, Sun Yat-sen Memorial Hospital, Sun Yat-sen University, Guangzhou, Guangdong, China \\ ${ }^{2}$ Department of Anesthesiology, The First Affiliated Hospital of Sun Yat-sen University, Guangzhou, Guangdong, China \\ *These authors contributed equally to this work \\ \#These authors took on the correspondence responsibility of this work equally \\ Correspondence to: Minghui Cao, email: caominghui_sysu@163.com \\ Wenqi Huang, email: huangwenqi86@aliyun.com
}

Keywords: oral tongue squamous cell carcinoma, marital status, SEER, survival analysis, biopsychosocial medical model

Received: March 06, 2017 Accepted: June 05, $2017 \quad$ Published: June 17, 2017

Copyright: Sun et al. This is an open-access article distributed under the terms of the Creative Commons Attribution License 3.0 (CC BY 3.0), which permits unrestricted use, distribution, and reproduction in any medium, provided the original author and source are credited.

\section{ABSTRACT}

Marital status was found to be an independent prognostic factor for survival in several cancers. However related researches of oral tongue squamous cell carcinoma (OTSCC) are still rare. We explored the Surveillance, Epidemiology, and End Results (SEER) program and finally identified 14,194 patients with OTSCC. Kaplan-Meier analysis and multivariate Cox regression models were used to distinguish risk factors for overall survival (OS) and tumor cause-specific survival (TCSS). Widowed patients had the highest percentage of female, highest average ages and more prevalence with localized SEER Stage significantly, while patients in the single group were younger than other groups. After univariate analysis and multivariate analysis, marital status was demonstrated to be an independent prognostic factor of OS and TCSS. Married patients showed better 5-year OS $(65.6 \%)$ and 5-year TCSS $(89.9 \%)$ than other patients. Subgroup survival analysis according to AJCC TNM stage and SEER stage showed that the widowed patients demonstrated worst OS and TCSS compared to other groups. Marital status was an important prognostic factor for survival in patients with OTSCC. Widowed patients exhibited with the highest risk of death compared with other groups.

\section{INTRODUCTION}

Cancers of lip and oral cavity affected about 300,373 new cases and killed 145,353 people all over the world in 2012 based on GLOBOCAN estimates [1]. Oral tongue squamous cell carcinoma (OTSCC) is oral cavity squamous cell carcinoma (OCSCC) originating from the tongue. Etiologically, tobacco smoking and alcohol use is two principal risk factors of OCSCC [2]. Besides tobacco and alcohol, infection with human papilloma virus (HPV) especially HPV 16 is strongly related with occurrence of tongue cancer [3]. OCSCC including OTSCC can be classified into stage I-IV according to the tumor node metastases (TNM) staging system of the American Joint Committee on Cancer (AJCC) [4]. For the AJCC stage I and II early OTSCCs the five-year survival rates was $67 \%$ and $51 \%$, while for stage III and IV advanced OTSCCs the five-year disease-specific survival rates was 39\% and $27 \%[5,6]$. Nowadays the notions of health and disease have more and more emphasized the position of social and psychological factors in disease development, which is also called biopsychosocial medical model [7, 8]. Nevertheless almost all the clinical studies of tongue cancer concentrated on the importance of clinical factors $[9,10]$, while few studies focused on the roles of social and psychological factors.

Stable marital status represents a solid marriage, which could lead to a positive social support and psychological state, and finally improves cancer survival [11]. It has been demonstrated that marital status acts as an independent prognostic factor for survival in several cancers, such as breast cancer, gastric cancer and pancreatic cancer [12-14]. However there is no study analyzing the influence of marital status on prognosis in oral tongue 
squamous cell carcinoma yet. Given that oral tongue squamous cell carcinoma has become a horrible threat worldwide, it is meaningful to investigate the relationship between marital status and tongue cancer survival.

The Surveillance, Epidemiology, and End Results (SEER) program are composed of 18 cancer registries covering approximately $30 \%$ of the population in the United States $[15,16]$. It provides complete patient data including demographic information, clinical records and follow-up data updated annually by the National Center for Health Statistics. In this study, we took use of SEER data to analyze the influence of marital status on survival in patients with oral tongue squamous cell carcinoma.

\section{RESULTS}

\section{Patient baseline characteristics}

With the inclusion criteria, we initially included 27,871 patients from the SEER database. Then we excluded seven patients who were less than 18 years, 7,711 patients with incomplete clinical information, 2,242 patients with unknown demographic information and 3,717 patients with unknown cause of death or unknown survival month. Finally we identified 14,194 eligible patients with oral tongue squamous cell carcinoma, including 10,137 (71.4\%) male and 4,057 (28.6\%) female patients. Of these, $8,298(58.5 \%)$ patients were married, 2,705 (19.1\%) were single, 2,001 (14.1\%) were divorced/separated and 1,190 $(8.4 \%)$ were widowed respectively. Baseline demographic information and clinical record of all the included patients were showed in Table 1. There were significant differences in gender, age, race, marital status, grade, AJCC TNM stage, SEER stage, therapy of surgery and therapy of radiation among different groups. Single patients were younger $(54.9 \pm 12.8$ years old $)$, had the lowest proportion $(79.4 \%)$ of white and the highest proportion (16.1\%) of black when compared with married, divorced/separated and widowed patients. Patients in the widowed group had the highest percentage $(67.2 \%)$ of female, highest average ages $(74.0 \pm 11.1$ years old) and more prevalence $(39.0 \%)$ with localized SEER Stage significantly. Widowed patients also had a larger proportion $(59.4 \%)$ of receiving surgery and a smaller proportion $(38.6 \%)$ of receiving radiation compared with others.

\section{The influence of marital status on overall survival (OS)}

Univariate analysis (Kaplan-Meier analysis) and multivariate analysis (multivariate Cox regression analysis) were used to evaluate the overall survival (OS) of oral tongue squamous cell carcinoma patients (Table 2 and Supplementary Table 1). The 5-year OS rate was $65.6 \%$ in the married group, $49.3 \%$ in the single group, $49.1 \%$ in the divorced/separated group and $37.5 \%$ in the widowed group respectively. Univariate analysis discovered age $(P<0.001)$, race $(P<0.001)$, marital status $(P<0.001)$, grade $(P<0.001)$, AJCC TNM stage $(P<0.001)$, SEER stage $(P<0.001)$, therapy of surgery $(P<0.001)$ and therapy of radiation $(P<0.001)$ as significant factors associated with OS. After including and adjusting all these significant variables in the multivariate analysis, all the factors containing age $(P<0.001)$, race $(P<0.001)$, marital status $(P<0.001)$, grade $(P<0.001)$, AJCC TNM stage $(P<0.001)$, SEER stage $(P<0.001)$, therapy of surgery $(P<0.001)$ and therapy of radiation $(P<0.001)$ remained as independent prognostic factors. When it came to marital status, married patients had better OS than other OTSCC patients (Single, HR [hazard ratio] 1.645, 95\% CI [confidence interval] 1.531-1.767, $P<0.001$; Divorced/ Separated, HR 1.517, 95\% CI 1.404-1.638, $P<0.001$; Widowed, HR 1.999, 95\% CI 1.829-2.185, $P<0.001$ ) (Figure 1).

\section{The influence of marital status on tumor cause- specific survival (TCSS)}

The tumor cause-specific survival (TCSS) were also calculated through univariate analysis (Kaplan-Meier analysis) and multivariate analysis (multivariate Cox regression analysis) (Table 3 and Supplementary Table 1). The 5-year TCSS rate of the married group was $89.9 \%$, while other 5-year TCSS rates were $85.8 \%$ in the single group, $81.2 \%$ in the divorced/separated group and $71.1 \%$ in the widowed group. Gender $(P<0.001)$, age $(P 0.001)$, race $(P<0.001)$, marital status $(P<0.001)$, AJCC TNM stage $(P<0.001)$, SEER stage $(P<0.001)$, therapy of surgery $(P<0.001)$ and therapy of radiation $(P<0.001)$ were found to be associated with TCSS by univariate analysis. When the previous variables were adjusted in multivariate analysis, it revealed gender $(P<0.001)$, age $(P<0.001)$, race $(P<0.001)$, marital status $(P<0.001)$, AJCC TNM stage $(P<0.001)$ and SEER stage $(P<0.001)$ as independent prognostic factors. Moreover, as for marital status, married patients had beneficial TCSS when compared with other OTSCC patients (Single, HR 1.603, 95\% CI 1.375-1.869, $P<0.001$; Divorced/Separated, HR 1.940, 95\% CI 1.675-2.247, $P<0.001$; Widowed, HR 2.493, 95\% CI 2.096-2.966, $P<0.001$ ) (Figure 2).

\section{Subgroup survival analysis stratified by AJCC TNM stage and SEER stage}

The prognostic effect of marital status on OS and TCSS was explored in each subgroup by multivariate analysis according to AJCC TNM stage and SEER stage (Table 4). We found that marital status still acted as an independent prognostic factor for OS $(P<0.001)$ and TCSS $(P<0.001)$ in each AJCC TNM stage and SEER stage after subgroup analysis. Similarly, married patients enjoyed better results for OS and TCSS in each subgroup, 
Table 1: Baseline characteristic of patients with oral tongue squamous cell carcinoma in SEER database

\begin{tabular}{|c|c|c|c|c|c|c|c|}
\hline \multicolumn{2}{|c|}{$\begin{array}{c}\text { Characteristic } \\
(\%)\end{array}$} & $\begin{array}{c}\text { Total } \\
(\%) \\
14194(100.0) \\
\end{array}$ & \multirow{2}{*}{$\begin{array}{c}\text { Married } \\
(\%) \\
8298(58.5) \\
\end{array}$} & \multirow{2}{*}{ 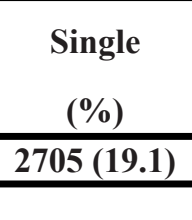 } & \multirow{2}{*}{$\begin{array}{c}\text { Divorced/ } \\
\text { Separated } \\
(\%) \\
2001(14.1) \\
\end{array}$} & $\begin{array}{c}\text { Widowed } \\
1190(8.4)\end{array}$ & $P$ value \\
\hline \multirow[t]{3}{*}{ Gender } & & & & & & & $<0.001$ \\
\hline & Male & $10137(71.4)$ & $6294(75.8)$ & $1994(73.7)$ & 1459 (72.9) & $390(32.8)$ & \\
\hline & Female & 4057 (28.6) & $2004(24.2)$ & $711(26.3)$ & $542(27.1)$ & $800(67.2)$ & \\
\hline \multirow[t]{2}{*}{ Age } & & & & & & & $<0.001$ \\
\hline & & $60.2 \pm 12.5$ & $60.0 \pm 12.1$ & $54.9 \pm 12.8$ & $60.1 \pm 10.1$ & $74.0 \pm 11.1$ & \\
\hline \multirow[t]{4}{*}{ Race } & & & & & & & $<0.001$ \\
\hline & White & $12218(86.1)$ & 7343 (88.5) & 2149 (79.4) & $1744(87.2)$ & $982(82.5)$ & \\
\hline & Black & $1059(7.5)$ & $328(4.0)$ & $436(16.1)$ & $180(9.0)$ & $115(9.7)$ & \\
\hline & Others & 917 (6.5) & $627(7.6)$ & $120(4.4)$ & 77 (3.8) & $93(7.8)$ & \\
\hline \multirow[t]{5}{*}{ Grade } & & & & & & & $<0.001$ \\
\hline & I & $2108(14.9)$ & $1247(15.0)$ & $388(14.3)$ & $264(13.2)$ & 209 (17.6) & \\
\hline & II & 6999 (49.3) & 3953 (47.6) & $1420(52.5)$ & 995 (49.7) & $631(53.0)$ & \\
\hline & III & $4967(35.0)$ & $3018(36.4)$ & $882(32.6)$ & $720(36.0)$ & $347(29.2)$ & \\
\hline & IV & $120(0.8)$ & $80(1.0)$ & $15(0.6)$ & $22(1.1)$ & $3(0.3)$ & \\
\hline \multirow[t]{5}{*}{ AJCC stage } & & & & & & & $<0.001$ \\
\hline & I & $3183(22.4)$ & $2035(24.5)$ & $520(19.2)$ & $313(15.6)$ & $315(26.5)$ & \\
\hline & II & $1672(11.8)$ & $942(11.4)$ & 294 (10.9) & 234 (11.7) & $202(17.0)$ & \\
\hline & III & $2392(16.9)$ & 1395 (16.8) & $471(17.4)$ & $319(15.9)$ & $207(17.4)$ & \\
\hline & IV & 6947 (48.9) & $3926(47.3)$ & $1420(52.5)$ & $1135(56.7)$ & $466(39.2)$ & \\
\hline \multirow[t]{4}{*}{ SEER stage } & & & & & & & $<0.001$ \\
\hline & Localized & 4345 (30.6) & $2678(32.3)$ & $742(27.4)$ & $461(23.0)$ & $464(39.0)$ & \\
\hline & Regional & $7316(51.5)$ & $4376(52.7)$ & $1359(50.2)$ & $1072(53.6)$ & $509(42.8)$ & \\
\hline & Distant & $2533(17.8)$ & $1244(15.0)$ & $604(22.3)$ & $468(23.4)$ & $217(18.2)$ & \\
\hline \multirow[t]{3}{*}{ Surgery } & & & & & & & $<0.001$ \\
\hline & Yes & $8000(56.4)$ & $4821(58.1)$ & $1491(55.1)$ & $981(49.0)$ & 707 (59.4) & \\
\hline & No & $6194(43.6)$ & 3477 (41.9) & $1214(44.9)$ & $1020(51.0)$ & $483(40.6)$ & \\
\hline \multirow[t]{3}{*}{ Radiation } & & & & & & & $<0.001$ \\
\hline & Yes & $6021(42.4)$ & $3411(41.1)$ & $1165(43.1)$ & $986(49.3)$ & 459 (38.6) & \\
\hline & No & $8173(57.6)$ & 4887 (58.9) & $1540(56.9)$ & $1015(50.7)$ & $731(61.4)$ & \\
\hline
\end{tabular}

Notes: AJCC, the American Joint Committee on Cancer; SEER, the Surveillance, Epidemiology and End Results.

while unmarried patients displayed a hazard ratio of mortality, among which the widowed patients almost exhibited with the highest risk (Supplementary Figure 1 and Supplementary Figure 2). However, we found no significant difference between the married and single group associated with OS in the subgroup of AJCC TNM stage I, as well as with TCSS in the subgroup of AJCC stage III.

\section{DISCUSSION}

In this study, we firstly explored the influence of marital status on overall survival and tumor cause- specific survival in patients with oral tongue squamous cell carcinoma. As a result, we found that the married patients experienced better overall survival and tumor cause-specific survival than the single, divorced/separated, widowed patients. It was discovered that married patients had beneficial survival results in oral tongue squamous cell carcinoma significantly, which remained even after adjusted for age, race, grade, AJCC TNM stage, SEER stage, therapy of surgery and therapy of radiation in multivariable analyses. Subgroup analysis confirmed the conservatory role of marriage based on different AJCC TNM stage and SEER stage. In addition, it pointed out that 
the widowed patients always endured the highest risk of mortality for OS and TCSS. The meaning of this study lies in the important impact of marital status on survival of oral tongue squamous cell carcinoma, which is in consistency with previous researches of other cancers [17-20].

Engel put forward a novel conception of biopsychosocial medical model replacing biomedical model in 1977 [7]. It attributed occurrence, development and outcome of diseases to biological factors like genetic element, psychological factors like mood or behavior element, and social factors like or familial or cultural element [21]. Since then, plenty of studies have been performed to dig out the relation between biopsychosocial factors and diverse diseases, such as ischemic heart disease, diabetes mellitus and chronic pain [22-24]. Gradually, importance has been attached to the function of biopsychosocial factors in cancer patients [25, 26]. A longitudinal study aiming at marital status and mortality in British women found that being single was associated with higher mortality instead of being divorced and being widowed [27]. Another research analyzed marital status and head and neck cancer outcomes based on 51,272 patients from SEER database, found that the married patients were less likely to present with metastatic disease, while the married patients were more likely to receive definitive treatment [17]. A cohort study in Swedish discovered that divorce, widowhood, living alone, low educational attainment, and low income increased the risk of subtypes in esophageal and gastric cancer [28]. Identically, our study found out that marital status of married patients played a beneficial role in survival outcomes of oral tongue squamous cell carcinoma patients, which was in accordance with the previous researches. Whereas, it emphasized the interrelated relationship between marital status and survival rather than the causal relationship. It is essential to dig out the latent mechanism how marital status influences survival outcomes in order to improve the outcome of tongue cancer patients [29].

Our result showed that marital status was found to be associated with survival in patients with oral tongue squamous cell carcinoma, but why marital status of married patients served as a protective factor? Firstly, a beatific marriage brought a comfortable, confident and enjoyable emotional state. So the married group of cancer patients could receive social support from friends and family, which would decrease their risk for psychological distress. Single patients were found to have high rates of distress [30]. Patients with depression symptoms suffered more during cancer treatment, and it was verified that less social support were associated with worse mortality [31]. The molecular mechanism involved several inflammatory biomarkers such as IL-1 $\beta$, IL-6, TNF and C-reactive protein [32]. Secondly, stable marriage in married patients always came with good family financial circumstances.

\section{Kaplan-Meier survival curve}

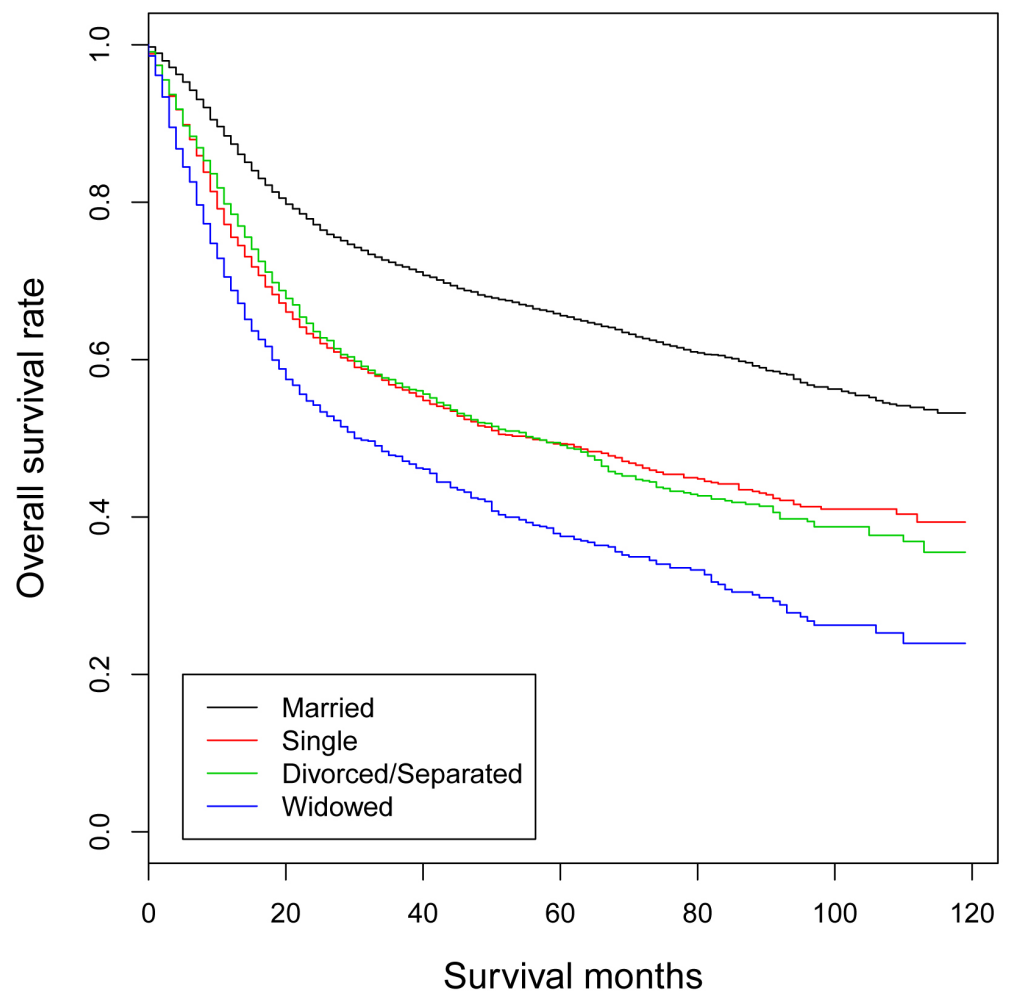

Figure 1: Kaplan-Meier survival curves: the overall survival in patients with oral tongue squamous cell carcinoma according to marital status. $\chi^{2}=569, P<0.001$. 
Table 2: Univariate and multivariate analysis for overall survival

\begin{tabular}{|c|c|c|c|c|c|c|c|}
\hline \multicolumn{2}{|c|}{ Characteristic } & 5-year OS & \multicolumn{2}{|c|}{ Univariate analysis } & \multicolumn{3}{|c|}{ Multivariate analysis } \\
\hline \multicolumn{4}{|l|}{ Gender } & $P$ value & HR & $95 \% \mathrm{CI}$ & \\
\hline & Male & $58.1 \%$ & 0.9 & 0.330 & & & \\
\hline & Female & $57.0 \%$ & & & & & \\
\hline \multirow[t]{3}{*}{ Age } & & & & & & & $<0.001$ \\
\hline & $<60$ & $64.8 \%$ & 285 & $<0.001$ & Reference & & \\
\hline & $\geq 60$ & $50.8 \%$ & & & 1.617 & $1.526-1.713$ & $<0.001$ \\
\hline \multirow[t]{4}{*}{ Race } & & & & & & & $<0.001$ \\
\hline & White & $59.4 \%$ & 244 & $<0.001$ & Reference & & \\
\hline & Black & $37.3 \%$ & & & 1.495 & $1.368-1.634$ & $<0.001$ \\
\hline & Others & $60.0 \%$ & & & 1.125 & $1.003-1.263$ & 0.045 \\
\hline \multicolumn{2}{|l|}{ Marital Status } & & & & & & $<0.001$ \\
\hline & Married & $65.6 \%$ & 569 & $<0.001$ & Reference & & \\
\hline & Single & $49.3 \%$ & & & 1.645 & $1.531-1.767$ & $<0.001$ \\
\hline & Divorced/Separated & $49.1 \%$ & & & 1.517 & $1.404-1.638$ & $<0.001$ \\
\hline & Widowed & $37.5 \%$ & & & 1.999 & $1.829-2.185$ & $<0.001$ \\
\hline \multirow[t]{5}{*}{ Grade } & & & & & & & $<0.001$ \\
\hline & I & $64.2 \%$ & 42.9 & $<0.001$ & Reference & & \\
\hline & II & $55.5 \%$ & & & 0.990 & $0.906-1.081$ & 0.819 \\
\hline & III & $58.3 \%$ & & & 0.803 & $0.729-0.884$ & $<0.001$ \\
\hline & IV & $62.3 \%$ & & & 0.752 & $0.547-1.033$ & 0.079 \\
\hline \multirow[t]{5}{*}{ AJCC stage } & & & 596 & $<0.001$ & & & $<0.001$ \\
\hline & I & $74.9 \%$ & & & Reference & & \\
\hline & II & $61.3 \%$ & & & 1.617 & $1.439-1.817$ & $<0.001$ \\
\hline & III & $57.0 \%$ & & & 1.814 & $1.552-2.119$ & $<0.001$ \\
\hline & IV & $49.2 \%$ & & & 1.974 & $1.686-2.311$ & $<0.001$ \\
\hline \multirow[t]{4}{*}{ SEER stage } & & & 1072 & $<0.001$ & & & $<0.001$ \\
\hline & Localized & $70.9 \%$ & & & Reference & & \\
\hline & Regional & $58.1 \%$ & & & 1.089 & $0.950-1.248$ & 0.220 \\
\hline & Distant & $34.3 \%$ & & & 2.004 & $1.722-2.332$ & $<0.001$ \\
\hline \multirow[t]{3}{*}{ Surgery } & & & & & & & $<0.001$ \\
\hline & Yes & $62.8 \%$ & 252 & $<0.001$ & Reference & & \\
\hline & No & $51.3 \%$ & & & 2.416 & $2.010-2.904$ & $<0.001$ \\
\hline \multirow[t]{3}{*}{ Radiation } & & & & & & & $<0.001$ \\
\hline & Yes & $52.2 \%$ & 184 & $<0.001$ & Reference & & \\
\hline & No & $61.9 \%$ & & & 2.238 & $1.864-2.687$ & $<0.001$ \\
\hline
\end{tabular}

Notes: OS, overall survival; HR, hazard ratio; CI, confidence interval; AJCC, the American Joint Committee on Cancer; SEER, the Surveillance, Epidemiology and End Results.

And the financial circumstances was associated with cancer survival, mainly explained by stage at diagnosis and differences in treatment [33]. Those with fine financial states were likely to obtain early medical examination and were consequently detected with early tumor stage. They could also receive early and better treatment [34]. Thirdly, compared with unmarried patients, married patients were linked with more nodes through more connection in the 
social network. And they may get more information about medical facilities, professional experts and treatments, contributing to a better prognosis [35]. Nowadays the complex cancer therapy made it difficult for the unmarried patients to follow up [36]. The social network impacted the patient's adherence, and a long-term adherence can affect patients' health outcomes [37]. Furthermore, low social network diversity was independently associated with more adverse lifestyle associated with prognosis [38].

Although we included a large number of sample size in this study, there existed several limitations interfering the results. Firstly, the information of marital status provided by the SEER database is not complete enough. It only offers marital status at diagnosis but lacks changes during the follow-up period. However, the alteration of marital status during the follow-up period probably affected the survival outcomes, since more than one half of patients with oral tongue squamous cell carcinoma would survive for five years. In addition, the patients prevalently aged more than 60 years old, implying the potential of transformation from married to widowed during the follow-up period. Secondly, besides marital status, there are many other social factors such as education, income and insurance included in the biopsychosocial medical model. While the SEER database are short of information about those other social factors, confusing the survival outcomes in the married patients. We had better take all these factors into account if possible. Thirdly, the contentment degree of marriage is unreachable in the SEER database. But even patients from the same married group own different marital satisfaction. For example, marital distress has negative health consequences over time through damaging immune system. So it is unavailable to explore relation between quantized marital status and survival [39]. Fourthly, it lacks more detailed clinical records like surgery and radiation information since diagnosis, which may contribute to bias. Fifthly, the SEER database did not take into account patients with sexual minority preferences including lesbian, gay, bisexual and transgender peoples. However, the factors of sexual orientation have been demonstrated to be associated with cancer survival by several studies [40-42]. As for subgroup analysis the size of each subgroup was relatively small. More studies with thorough information and larger sample size in the future are necessary to prove our results.

Besides, there are a number of well-known inherent limitations in the SEER database. On one hand, some measures are problematic. For example, behavioral and other patient risk factors such as smoking or alcohol use, body mass index (BMI) and personal or family history are incomplete, which may affect the cancer survival. Additionally, information about recurrence is seldom

\section{Kaplan-Meier survival curve}

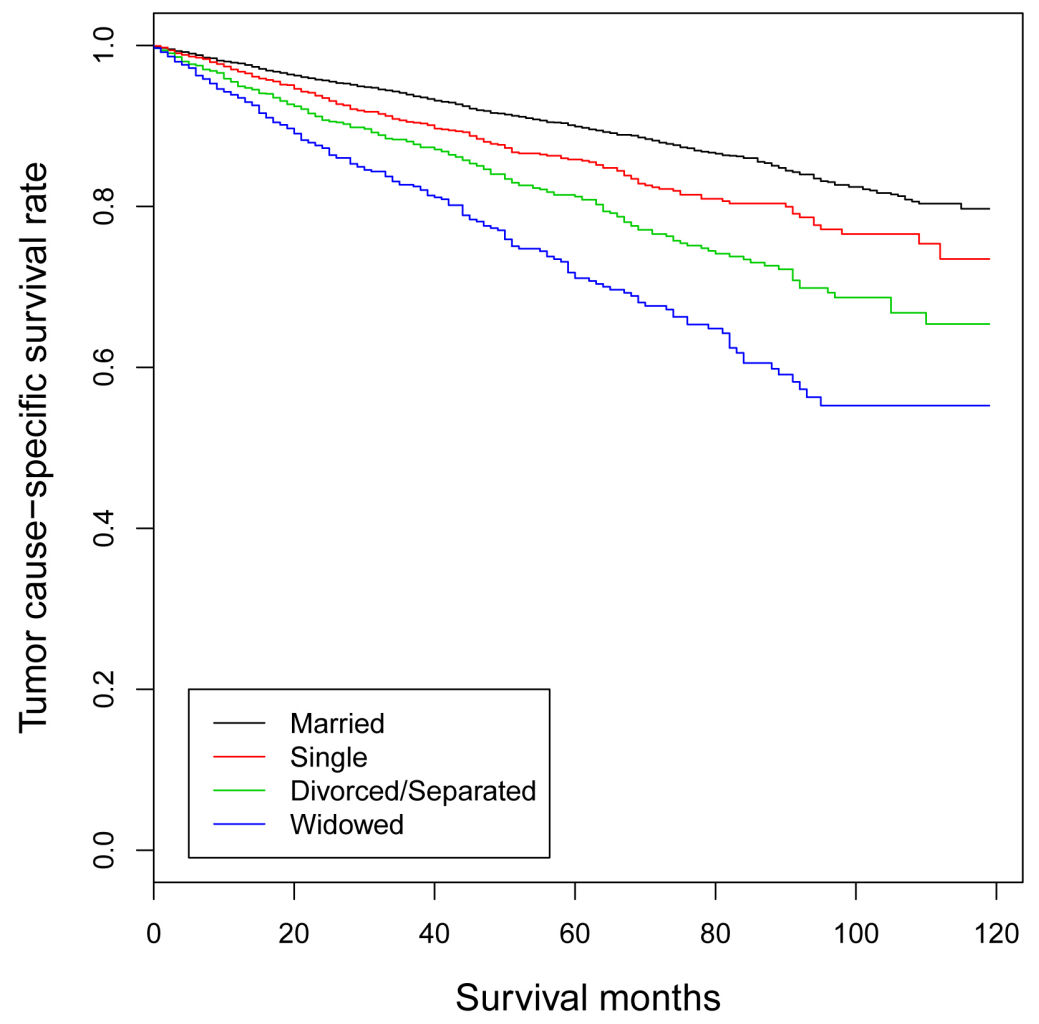

Figure 2: Kaplan-Meier survival curves: the tumor cause-specific survival in patients with oral tongue squamous cell carcinoma according to marital status. $\chi^{2}=238, P<0.001$. 
Table 3: Univariate and multivariate analysis for tumor cause-specific survival

\begin{tabular}{|c|c|c|c|c|c|c|c|}
\hline \multirow{2}{*}{\multicolumn{2}{|c|}{ Characteristic }} & \multirow[b]{2}{*}{$\begin{array}{l}\text { 5-year } \\
\text { TCSS }\end{array}$} & \multicolumn{2}{|c|}{ Univariate analysis } & \multicolumn{3}{|c|}{ Multivariate analysis } \\
\hline & & & $\begin{array}{c}\text { Log Rank } \\
\chi^{2} \text { test }\end{array}$ & $P$ value & HR & $95 \% \mathrm{CI}$ & $P$ value \\
\hline \multirow[t]{3}{*}{ Gender } & & & & & & & $<0.001$ \\
\hline & Male & $86.5 \%$ & 4.4 & 0.036 & Reference & & \\
\hline & Female & $87.1 \%$ & & & 0.689 & $0.601-0.789$ & $<0.001$ \\
\hline \multirow[t]{3}{*}{ Age } & & & & & & & $<0.001$ \\
\hline & $<60$ & $92.6 \%$ & 308 & $<0.001$ & Reference & & \\
\hline & $\geq 60$ & $80.3 \%$ & & & 2.635 & $2.332-2.978$ & $<0.001$ \\
\hline \multirow[t]{4}{*}{ Race } & & & & & & & $<0.001$ \\
\hline & White & $87.0 \%$ & 27.6 & $<0.001$ & Reference & & \\
\hline & Black & $78.9 \%$ & & & 1.450 & $1.193-1.762$ & $<0.001$ \\
\hline & Others & $89.2 \%$ & & & 0.864 & $0.674-1.107$ & 0.247 \\
\hline \multicolumn{2}{|c|}{ Marital Status } & & & & & & $<0.001$ \\
\hline & Married & $89.9 \%$ & 238 & $<0.001$ & Reference & & \\
\hline & Single & $85.8 \%$ & & & 1.603 & $1.375-1.869$ & $<0.001$ \\
\hline & Divorced/Separated & $81.2 \%$ & & & 1.940 & $1.675-2.247$ & $<0.001$ \\
\hline & Widowed & $71.1 \%$ & & & 2.493 & $2.096-2.966$ & $<0.001$ \\
\hline \multicolumn{8}{|l|}{ Grade } \\
\hline & I & $87.1 \%$ & 3.9 & 0.274 & & & \\
\hline & II & $85.9 \%$ & & & & & \\
\hline & III & $87.6 \%$ & & & & & \\
\hline & IV & $84.0 \%$ & & & & & \\
\hline \multirow[t]{5}{*}{ AJCC stage } & & & 17 & $<0.001$ & & & $<0.001$ \\
\hline & I & $87.9 \%$ & & & Reference & & \\
\hline & II & $84.9 \%$ & & & 1.279 & $1.062-1.540$ & 0.009 \\
\hline & III & $85.6 \%$ & & & 1.211 & $0.925-1.585$ & 0.163 \\
\hline & IV & $87.1 \%$ & & & 0.957 & $0.727-1.258$ & 0.751 \\
\hline \multirow[t]{4}{*}{ SEER stage } & & & 59.7 & $<0.001$ & & & $<0.001$ \\
\hline & Localized & $87.1 \%$ & & & Reference & & \\
\hline & Regional & $87.9 \%$ & & & 0.933 & $0.736-1.182$ & 0.565 \\
\hline & Distant & $81.5 \%$ & & & 1.664 & $1.255-2.206$ & $<0.001$ \\
\hline \multirow[t]{3}{*}{ Surgery } & & & 10.9 & $<0.001$ & & & \\
\hline & Yes & $87.3 \%$ & & & & & \\
\hline & No & $85.9 \%$ & & & & & \\
\hline \multicolumn{8}{|l|}{ Radiation } \\
\hline & Yes & $86.2 \%$ & 6.1 & 0.014 & & & \\
\hline & No & $87.1 \%$ & & & & & \\
\hline
\end{tabular}

Notes: TCSS, tumor cause-specific survival; HR, hazard ratio; CI, confidence interval; AJCC, the American Joint Committee on Cancer; SEER, the Surveillance, Epidemiology and End Results.

collected by any SEER registry $[43,44]$. On the other hand, some important measures can't be achieved from the SEER database. Firstly, there is no patient self-reported information including functional status or patient's quality of life (QoL) in the SEER data, and the information reflect patients' survival quality. Secondly, the SEER data only record the vital status during follow-up. Neither information of metastasis occurring after initial diagnosis 
Table 4: Multivariate analysis of marital status for overall survival and tumor cause-specific survival

\begin{tabular}{|c|c|c|c|c|c|c|c|}
\hline \multirow{2}{*}{ Variable } & & \multicolumn{3}{|c|}{ Overall survival } & \multicolumn{3}{|c|}{ Tumor cause-specific survival } \\
\hline & & HR & $95 \% \mathrm{CI}$ & $P$ value & HR & $95 \% \mathrm{CI}$ & $P$ value \\
\hline \multicolumn{8}{|c|}{ SEER stage } \\
\hline \multicolumn{8}{|c|}{ Localized } \\
\hline & Married & Reference & & & Reference & & \\
\hline & Single & 1.369 & $1.156-1.621$ & $<0.001$ & 1.431 & $1.084-1.890$ & 0.012 \\
\hline & Divorced/Separated & 1.366 & $1.135-1.644$ & $<0.001$ & 1.633 & $1.232-2.164$ & $<0.001$ \\
\hline & Widowed & 1.944 & $1.633-2.315$ & $<0.001$ & 2.619 & $2.013-3.407$ & $<0.001$ \\
\hline \multicolumn{8}{|l|}{ Regional } \\
\hline & Married & Reference & & & Reference & & \\
\hline & Single & 1.760 & $1.591-1.946$ & $<0.001$ & 1.672 & $1.331-2.100$ & $<0.001$ \\
\hline & Divorced/Separated & 1.518 & $1.362-1.692$ & $<0.001$ & 2.007 & $1.624-2.480$ & $<0.001$ \\
\hline & Widowed & 1.977 & $1.723-2.269$ & $<0.001$ & 2.696 & $2.048-3.550$ & $<0.001$ \\
\hline \multicolumn{8}{|l|}{ Distant } \\
\hline & Married & Reference & & & Reference & & \\
\hline & Single & 1.545 & $1.355-1.763$ & $<0.001$ & 1.662 & $1.206-2.290$ & 0.002 \\
\hline & Divorced/Separated & 1.506 & $1.311-1.730$ & $<0.001$ & 2.139 & $1.578-2.900$ & $<0.001$ \\
\hline & Widowed & 1.710 & $1.420-2.060$ & $<0.001$ & 1.680 & $1.078-2.618$ & 0.022 \\
\hline \multicolumn{8}{|c|}{ AJCC stage } \\
\hline \multicolumn{8}{|c|}{ I } \\
\hline & Married & Reference & & & Reference & & \\
\hline & Single & 1.207 & $0.964-1.512$ & 0.101 & 1.434 & $1.020-2.017$ & 0.038 \\
\hline & Divorced/Separated & 1.455 & $1.151-1.841$ & 0.002 & 1.641 & $1.157-2.327$ & 0.005 \\
\hline & Widowed & 1.778 & $1.422-2.222$ & $<0.001$ & 2.555 & $1.845-3.538$ & $<0.001$ \\
\hline \multicolumn{8}{|l|}{ II } \\
\hline & Married & Reference & & & Reference & & \\
\hline & Single & 1.778 & $1.423-2.221$ & $<0.001$ & 2.045 & $1.371-3.051$ & $<0.001$ \\
\hline & Divorced/Separated & 1.408 & $1.107-1.792$ & 0.005 & 2.112 & $1.454-3.069$ & $<0.001$ \\
\hline & Widowed & 2.014 & $1.594-2.544$ & $<0.001$ & 2.383 & $1.567-3.623$ & $<0.001$ \\
\hline \multicolumn{8}{|l|}{ III } \\
\hline & Married & Reference & & & Reference & & \\
\hline & Single & 1.747 & $1.475-2.070$ & $<0.001$ & 1.409 & $0.986-2.014$ & 0.060 \\
\hline & Divorced/Separated & 1.534 & $1.268-1.856$ & $<0.001$ & 1.756 & $1.244-2.480$ & 0.001 \\
\hline & Widowed & 1.868 & $1.511-2.309$ & $<0.001$ & 1.959 & $1.308-2.936$ & 0.001 \\
\hline \multicolumn{8}{|l|}{ IV } \\
\hline & Married & Reference & & & Reference & & \\
\hline & Single & 1.666 & $1.519-1.827$ & $<0.001$ & 1.629 & $1.298-2.044$ & $<0.001$ \\
\hline & Divorced/Separated & 1.541 & $1.397-1.700$ & $<0.001$ & 2.073 & $1.675-2.564$ & $<0.001$ \\
\hline & Widowed & 1.976 & $1.733-2.253$ & $<0.001$ & 2.686 & $2.000-3.607$ & $<0.001$ \\
\hline
\end{tabular}

Notes: HR, hazard ratio; CI, confidence interval; SEER, the Surveillance, Epidemiology and End Results; AJCC, the American Joint Committee on Cancer.

nor site of metastasis is provided [45, 46]. Thirdly, test results from lab tests and imaging are not supplied in the SEER database. So the data of tumor marker associated with cancer survival are missing for analysis further.
In spite of those limitations mentioned above, we affirmed the beneficial survival results of married patients in oral tongue squamous cell carcinoma. On the contrary, unmarried patients suffered from high risk of 
overall and tumor cause-specific mortality. Particularly the widowed patients always endured the highest risk of mortality among the unmarried patients. According to the biopsychosocial medical model, it is the underlying psychological and social support that produces a protective power, improving the final survival outcomes [47, 48]. So, when it comes to healthcare providers, these patients faced with higher risk of mortality demand more elaborate care in clinical practice, to strengthen the psychosocial support and construct their social network.

\section{MATERIALS AND METHODS}

\section{Data sources}

The open dataset was obtained from the Surveillance, Epidemiology, and End Results database released in November 2015 through internet access (https://seer. cancer.gov). It included demographic information like age, sex, race, marital status, and clinical records of stage, grade, therapy, as well as follow-up data. We took the SEER November 2015 Research Data for analyses, which contained the SEER 18 registries Research Data and the Hurricane Katrina Impacted Louisiana Cases from 1973 to 2013.

\section{Inclusion and exclusion criteria}

We extracted patients with oral tongue squamous cell carcinoma (International Classification of Diseases for Oncology, Third Edition [ICD-O-3], code C01.9, C02.0, C02.1, C02.2, C02.3, C02.4, C02.8, C02.9) for our study. Patients were included when meeting the following criteria: (1) patients were aged 18 years or older at diagnosis; (2) oral tongue carcinoma was diagnosed between 2004 and 2013; (3) histological types were limited to squamous cell carcinoma (code 8050, 8051, 8052, 8070, 8071, 8072, 8073, 8074, 8075, 8076, 8081, 8082, 8083 and 8084). Patients were excluded according to the following criteria: (1) age at diagnosis was less than 18 years; (2) incomplete clinical information; (3) unknown demographic information; (4) unknown cause of death or unknown survival month.

\section{Statistical analysis}

Data of gender, age, race, marital status, grade, AJCC TNM stage, SEER stage, therapy, cause of death and survival months were collected from the SEER database. We described continuous variables as means and standard deviations, while described categorical variables as frequencies and percentages. For categorical variables, we chose the Pearson's chi-squared test and Fisher's exact tests to detect the statistical difference. For continuous variables, we chose independent Student's $t$-test and Analysis of Variance (ANOVA). When homogeneity of variance did not correspond, nonparametric test of Kruskal-Wallis test was adopted. Besides, we selected Kaplan-Meier analysis and multivariate Cox regression models to distinguish risk factors for overall survival (OS) and tumor cause-specific survival (TCSS). For overall survival analysis, any cause of deaths was defined as events and survivors were defined as censored events. For tumor cause-specific survival, deaths caused by tongue cancer were considered as events and deaths by other causes or survivors were considered as censored events. All the data analysis in this study was conducted by $\mathrm{R}$ statistical software version 3.3 (https:// www.r-project.org). All $P$ values were two-sided and $P<0.05$ was considered significant.

\section{Abbreviations}

OTSCC: Oral tongue squamous cell carcinoma. OCSCC: oral cavity squamous cell carcinoma. HPV: Human papilloma virus. TNM: Tumor node metastases. AJCC: The American Joint Committee on Cancer. SEER: The Surveillance, Epidemiology, and End Results. OS: Overall survival. TCSS: Tumor cause-specific survival. HR: Hazard ratio. CI: Confidence interval. ICD-O-3: International Classification of Diseases for Oncology, Third Edition.

\section{Authors' contributions}

SW, QZT, HWQ and CMH contributed to the study design. SW, QZT, TWL and LZQ contributed to the analyses. TWL, WZX and HWQ contributed to the preparation of tables and Figures. All authors contributed to writing and revising the manuscript. All authors reviewed the manuscript and agreed to this information before submission.

\section{ACKNOWLEDGMENTS}

The authors acknowledge the efforts of the Surveillance, Epidemiology, and End Results (SEER) Program tumor registries for the creation and maintenance of the open database.

\section{CONFLICTS OF INTEREST}

All of the authors have no conflicts of interest to declare.

\section{FUNDING}

This study was supported by National Natural Science Foundation of China (81272892, 81471352).

\section{REFERENCES}

1. Torre LA, Bray F, Siegel RL, Ferlay J, Lortet-Tieulent J, Jemal A. Global cancer statistics, 2012. CA Cancer J Clin. 2015; 65:87-108. 
2. Blot WJ, McLaughlin JK, Winn DM, Austin DF, Greenberg RS, Preston-Martin S, Bernstein L, Schoenberg JB, Stemhagen A, Fraumeni JF Jr. Smoking and drinking in relation to oral and pharyngeal cancer. Cancer Res. 1988; 48:3282-87.

3. Castellsagué X, Alemany L, Quer M, Halec G, Quirós B, Tous S, Clavero O, Alòs L, Biegner T, Szafarowski T, Alejo M, Holzinger D, Cadena E, et al, and ICO International HPV in Head and Neck Cancer Study Group. HPV Involvement in Head and Neck Cancers: Comprehensive Assessment of Biomarkers in 3680 Patients. J Natl Cancer Inst. 2016; 108:djv403.

4. Edge S, David R, Byrd DR, Compton CC, Fritz AG, Greene F, Trotti A, editors. AJCC cancer staging handbook. 7th ed. Springer-Verlag, New York. 2010.

5. Rusthoven K, Ballonoff A, Raben D, Chen C. Poor prognosis in patients with stage I and II oral tongue squamous cell carcinoma. Cancer. 2008; 112:345-51.

6. Sessions DG, Lenox J, Spector GJ, Chao C, Chaudry OA. Analysis of treatment results for base of tongue cancer. Laryngoscope. 2003; 113:1252-61.

7. Engel GL. The need for a new medical model: a challenge for biomedicine. Science. 1977; 196:129-36.

8. Adler RH. Engel's biopsychosocial model is still relevant today. J Psychosom Res. 2009; 67:607-11.

9. Kantola S, Parikka M, Jokinen K, Hyrynkangs K, Soini Y, Alho OP, Salo T. Prognostic factors in tongue cancer-relative importance of demographic, clinical and histopathological factors. Br J Cancer. 2000; 83:614-19.

10. Yokota T, Iida Y, Ogawa H, Kamijo T, Onozawa Y, Todaka A, Hamauchi S, Onoe T, Nakagawa M, Yurikusa T, Tanuma A, Yamashita A, Nishimura T, et al. Prognostic Factors and Multidisciplinary Postoperative Chemoradiotherapy for Clinical T4a Tongue Cancer. Oncology. 2016; 91:78-84.

11. Nipp RD, El-Jawahri A, Fishbein JN, Eusebio J, Stagl JM, Gallagher ER, Park ER, Jackson VA, Pirl WF, Greer JA, Temel JS. The relationship between coping strategies, quality of life, and mood in patients with incurable cancer. Cancer. 2016; 122:2110-16.

12. Shi RL, Chen Q, Yang Z, Pan G, Zhang Z, Wang W, Liu S, Zhang D, Jiang D, Liu W. Marital status independently predicts gastric cancer survival after surgical resection - an analysis of the SEER database. Oncotarget. 2016; 7:1322835. https://doi.org/10.18632/oncotarget.7107.

13. Osborne C, Ostir GV, Du X, Peek MK, Goodwin JS. The influence of marital status on the stage at diagnosis, treatment, and survival of older women with breast cancer. Breast Cancer Res Treat. 2005; 93:41-47.

14. Wang XD, Qian JJ, Bai DS, Li ZN, Jiang GQ, Yao J. Marital status independently predicts pancreatic cancer survival in patients treated with surgical resection: an analysis of the SEER database. Oncotarget. 2016; 7:24880-87. https://doi. org/10.18632/oncotarget.8467.

15. Hayat MJ, Howlader N, Reichman ME, Edwards BK. Cancer statistics, trends, and multiple primary cancer analyses from the Surveillance, Epidemiology, and End Results (SEER) Program. Oncologist. 2007; 12:20-37.

16. Hankey BF, Ries LA, Edwards BK. The surveillance, epidemiology, and end results program: a national resource. Cancer Epidemiol Biomarkers Prev. 1999; 8:1117-21.

17. Inverso G, Mahal BA, Aizer AA, Donoff RB, Chau NG, Haddad RI. Marital status and head and neck cancer outcomes. Cancer. 2015; 121:1273-78.

18. Qiu M, Yang D, Xu R. Impact of marital status on survival of gastric adenocarcinoma patients: Results from the Surveillance Epidemiology and End Results (SEER) Database. Sci Rep. 2016; 6:21098.

19. Hinyard L, Wirth LS, Clancy JM, Schwartz T. The effect of marital status on breast cancer-related outcomes in women under 65: A SEER database analysis. Breast. 2017; 32:13-17.

20. Wu C, Chen P, Qian JJ, Jin SJ, Yao J, Wang XD, Bai DS, Jiang GQ. Effect of marital status on the survival of patients with hepatocellular carcinoma treated with surgical resection: an analysis of 13,408 patients in the surveillance, epidemiology, and end results (SEER) database. Oncotarget. 2016; 7:79442-52. https://doi.org/10.18632/ oncotarget.12722.

21. Engel GL. The clinical application of the biopsychosocial model. J Med Philos. 1981; 6:101-23.

22. Gatchel RJ, Peng YB, Peters ML, Fuchs PN, Turk DC. The biopsychosocial approach to chronic pain: scientific advances and future directions. Psychol Bull. 2007; 133:581-624.

23. Calobrisi A. Biopsychosocial study of diabetes mellitus. Psychother Psychosom. 1983; 39:193-200.

24. Floud S, Balkwill A, Canoy D, Wright FL, Reeves GK, Green J, Beral V, Cairns BJ, and Million Women Study Collaborators. Marital status and ischemic heart disease incidence and mortality in women: a large prospective study. BMC Med. 2014; 12:42.

25. He XK, Lin ZH, Qian Y, Xia D, Jin P, Sun LM. Marital status and survival in patients with primary liver cancer. Oncotarget. 2017; 8:64954-64963. https://doi.org/10.18632/ oncotarget.11066.

26. Li M, Dai CY, Wang YN, Chen T, Wang L, Yang P, Xie D, Mao R, Chen C. Marital status is an independent prognostic factor for tracheal cancer patients: an analysis of the SEER database. Oncotarget. 2016; 7:77152-62. https://doi. org/10.18632/oncotarget.12809.

27. Cheung YB. Marital status and mortality in British women: a longitudinal study. Int J Epidemiol. 2000; 29:93-99.

28. Lagergren J, Andersson G, Talbäck M, Drefahl S, Bihagen E, Härkönen J, Feychting M, Ljung R. Marital status, education, and income in relation to the risk of esophageal and gastric cancer by histological type and site. Cancer. 2016; 122:207-12.

29. Goodwin JS, Hunt WC, Key CR, Samet JM. The effect of marital status on stage, treatment, and survival of cancer patients. JAMA. 1987; 258:3125-30. 
30. Goldzweig G, Andritsch E, Hubert A, Brenner B, Walach N, Perry S, Baider L. Psychological distress among male patients and male spouses: what do oncologists need to know? Ann Oncol. 2010; 21:877-83.

31. Sullivan DR, Forsberg CW, Ganzini L, Au DH, Gould MK, Provenzale D, Lyons KS, Slatore CG. Depression symptom trends and health domains among lung cancer patients in the CanCORS study. Lung Cancer. 2016; 100:102-09.

32. Miller AH, Raison CL. The role of inflammation in depression: from evolutionary imperative to modern treatment target. Nat Rev Immunol. 2016; 16:22-34.

33. Woods LM, Rachet B, Coleman MP. Origins of socioeconomic inequalities in cancer survival: a review. Ann Oncol. 2006; 17:5-19.

34. Lejeune C, Sassi F, Ellis L, Godward S, Mak V, Day M, Rachet B. Socio-economic disparities in access to treatment and their impact on colorectal cancer survival. Int J Epidemiol. 2010; 39:710-17.

35. Iwashyna TJ, Christakis NA. Marriage, widowhood, and health-care use. Soc Sci Med. 2003; 57:2137-47.

36. Kravdal H, Syse A. Changes over time in the effect of marital status on cancer survival. BMC Public Health. 2011; 11:804-804

37. DiMatteo MR, Haskard KB, Williams SL. Health beliefs, disease severity, and patient adherence: a meta-analysis. Med Care. 2007; 45:521-28.

38. Kroenke CH, Michael YL, Shu XO, Poole EM, Kwan ML, Nechuta S, Caan BJ, Pierce JP, Chen WY. Post-diagnosis social networks, and lifestyle and treatment factors in the After Breast Cancer Pooling Project. Psychooncology. 2017; 26:544-552.

39. Jaremka LM, Glaser R, Malarkey WB, Kiecolt-Glaser JK. Marital distress prospectively predicts poorer cellular immune function. Psychoneuroendocrinology. 2013; 38:2713-19.
40. Boehmer U, Glickman M, Milton J, Winter M. Healthrelated quality of life in breast cancer survivors of different sexual orientations. Qual Life Res. 2012; 21:225-36.

41. Boehmer U, Miao X, Ozonoff A. Cancer survivorship and sexual orientation. Cancer. 2011; 117:3796-804.

42. Boehmer U, Glickman M, Winter M, Clark MA. Breast cancer survivors of different sexual orientations: which factors explain survivors' quality of life and adjustment? Ann Oncol. 2013; 24:1622-30.

43. Warren JL, Mariotto A, Melbert D, Schrag D, Doriarose P, Penson D, Yabroff KR. Sensitivity of Medicare claims to identify cancer recurrence in elderly colorectal and breast cancer patients. Med Care. 2016; 54:e47-54.

44. Hassett MJ, Ritzwoller DP, Taback N, Carroll N, Cronin AM, Ting GV, Schrag D, Warren JL, Hornbrook MC, Weeks JC. Validating billing/encounter codes as indicators of lung, colorectal, breast, and prostate cancer recurrence using 2 large contemporary cohorts. Med Care. 2014; 52:e65-73.

45. Chawla N, Yabroff KR, Mariotto A, Mcneel TS, Schrag D, Warren JL. Accuracy and completeness of diagnosis codes for cancer metastasis on Medicare claims. J Clin Oncol. 2013 (Suppl); 31:6521.

46. Whyte JL, Engel-Nitz NM, Teitelbaum A, Gomez Rey G, Kallich JD. An Evaluation of Algorithms for Identifying Metastatic Breast, Lung, or Colorectal Cancer in Administrative Claims Data. Med Care. 2015; 53:e49-57.

47. Li S, Stampfer MJ, Williams DR, VanderWeele TJ. Association of Religious Service Attendance With Mortality Among Women. JAMA Intern Med. 2016; 176:777-85.

48. Bellardita L, Rancati T, Alvisi MF, Villani D, Magnani T, Marenghi C, Nicolai N, Procopio G, Villa S, Salvioni R, Valdagni R. Predictors of health-related quality of life and adjustment to prostate cancer during active surveillance. Eur Urol. 2013; 64:30-36. 